\title{
THỰC TRANG Ô NHIỄM VI SINH TRONG NƯỚC UỐNG ĐÓNG CHAI TẠI KHU VỰC 5 TİNH TÂY NGUYÊN
}

Nguyễn Vũ Thuận*, Phạm Văn Doanh, Nguyễn Thị Thu Hiền Khoa Dinh dữ̛ng Thực phẩm - Viện Vệ sinh dịch tễ Tây Nguyên

(Ngày đến tòa soạn: 4/6/2019; Ngày sưa bài sau phản biện: 26/8/2019;

Ngày chấp nhận đăng: 05/9/2019)

\section{Tóm tắt}

Khảo sát thực trạng ô nhiễm vi sinh 390 mẫu nước uống đóng chai về các chỉ tiêu Escherichia coli, Clostridia, Coliform tổng số, Streptococci feacal, Pseudomonas aeruginosa. Kết quả tỷ lệ nhiễm vi sinh $\mathrm{t}$ trong nước uống đóng chai năm 2017 là $56,7 \%$ năm 2018 là $50,7 \%$. Các chỉ tiêu vi sinh không đạt gồm có: Pseudomonas aeruginosa 41,5\%, Coliform tổng số 11,8\%, Clostridia 4,6\%; Escherichia coli $4,9 \%$; Streptococci feacal 1,3\%. Cần tăng cường công tác kiểm tra, giám sát, tuyên truyền, giáo dục đưa ra những cảnh báo nguy cơ, đảm bảo chất lượng nước và nâng cao nhận thức của người sản xuất, kinh doanh, tiêu dùng.

Tù khóa: Nước uống đóng chai, ô nhiễm vi sinh, chất luợng nước.

\section{1. ĐẶT VẤN ĐỀ}

Nhu cầu sử dụng nước uống đóng chai của người tiêu dùng ngày càng tăng cao. Để đáp ứng nhu cầu người tiêu dùnghàng loạt các cở sở sản xuất nước uống đóng chai ra đời với rất nhiều chủng loại, mẫu mã khác nhau. Tuy nhiên, vì mục đích lợi nhuận các cơ sở sản xuất đã không tuân thủ quy trình đảm bảo an toàn thực phẩm trong sản xuất, nên sản phẩm nước uống đóng chai đưa ra thị trường không đạt tiêu chuẩn sản phẩm. Ngoài ra quá trình vận chuyển và bảo quản, nước uống đóng chai trước khi tới tay người tiêu dùng không đảm bảo cũng làm tăng nguy coô nhiễm vi sinh vật.

Để đảm bảo chất lượng nước uống đóng chai an toàn đến tay người tiêu dùng và đưa ra cảnh báo, bảo vệ sức khỏe của cộng đồng chúng tôi tiến hành: "Đánh giá mức độ ô nhiễm vi sinh trong nước uống đóng chai tại khu vực 05 tỉnh Tây Nguyên" với mục tiêu: xác định tỷ lệ ô nhiễm vi sinh trong nước uống đóng chai lưu thông trên thị trường tại 5 tỉnh Tây Nguyên.

\section{2. ĐỐI TƯợNG VÀ PHƯƠNG PHÁP NGHIÊN CÚ'U}

\section{1. Đối tượng, địa điểm và thời gian nghiên cứu}

390 mẫu nước uống đóng chai được lấy ngẫu nhiên trên địa bàn 05 tỉnh Tây Nguyên (Kon Tum, Gia Lai, Đắk Lắk, Đăk Nông, Lâm Đồng) trong năm 2017 và năm 2018.

\subsection{Thiết kế nghiên cứu}

Nghiên cứu hồi cứu và phân tích từ kết quả giám sát chất lượng thực phẩm năm 2017 - 2018.

\subsection{Phương pháp lấy mẫu và đánh giá kết quả}

\subsubsection{Phương pháp lấy mẫu}

Mẫu nước uống đóng chai được lấy ngẫu nhiên trên thị trường, mẫu là sản phẩm chứa trong vật chứa bao bì nguyên vẹn, chưa mở. Mẫu được bảo quản, vận chuyển, bàn giao mẫu đảm bảo phù

\footnotetext{
*Điện thoại:0945912192Ｅmail:thuanvsdttn@gmail.com
} 
hợp với các yêu cầu về bảo quản do nhà sản xuất công bố [2]. Mẫu được gửi đến Trung tâm kiểm nghiệm an toàn vệ sinh thực phẩm - Viện vệ sinh Dịch tễ Tây Nguyên phân tích các chỉ số vi sinh.

\subsubsection{Phưong pháp phân tích}

- Sử dụng các phương pháp tiêu chuẩn Việt Nam, thế giới

+ Coliform tổng số: TCVN 6187-1:2009

+ Escherichia coli: TCVN 6187-1:2009

+ Streptococci feacal: TCVN 6189 -2:2009

+ Pseudomonas aeruginosa: ISO 16266:2006 (E)

+ Clostridia: TCVN 6191-2:1996

\subsection{3. Đánh giá kết quả}

Kết quả phân tích được đánh giá đạt hay không đạt theo Quy chuẩn kỹ thuật quốc gia đối với nước khoáng thiên nhiên và nước uống đóng chai QCVN 6-1:2010/BYT của Bộ Y tế ban hành kèm theo Thông tư 34/2010/TT-BYT ngày 02 tháng 6 năm 2010[1]. Kết quả xử lý bằng phần mềm Excel.

\section{KẾT QUẢ VÀ BÀN LUẬN}

3.1. Tình trạng ô nhiễm vi sinh vật trong sản phẩm nước uống đóng chai từ năm 2017 đến năm 2018

Bảng 1. Tình trạng ô nhiễm nuớc uống dovi sinh vật theo năm (\%)

\begin{tabular}{cccc}
\hline Năm & Sổ mẫu giám sát (n) & Số mẫu không đạt & Tỷ lệ \% không đạt \\
\hline 2017 & 120 & 68 & 56,7 \\
2018 & 270 & 137 & 50,7 \\
\hline Tổng cộng & $\mathbf{3 9 0}$ & $\mathbf{2 0 5}$ & $\mathbf{5 2 , 6}$ \\
\hline
\end{tabular}

Kết quả cho thấy trong 390 mẫu nghiên cứu từ năm 2017 đến năm 2018, có 205 mẫu không đạt về chỉ tiêu vi sinh chiếm 52,6\%. Trong đó năm 2017 kết quả phân tích 120 mẫu có 68 mẫu không đạt chiếm 46,7\%, năm 2018 kết quả phân tích 270 mẫu có 137 mẫu không đạt chiếm 50,7\%. Kết quả nghiên cứu cao hơn so với nghiên cứu Trần Thị Ánh Hồng và cộng sự năm 2012 chỉ có $36 \%$ mẫu nước uống đóng chai ở Bình Định nhiễm vi sinh vật [3]. Nhưng kết quả nghiên cứu này tương đương với kết quả nghiên cứu Nguyễn Vũ Thuận và cộng sự năm 2014-2015 cũng tại khu vực Tây Nguyên, có đến $50,3 \%$ mẫu nhiễm vi sinh [6]. Như vậy tình hình ô nhiễm vi sinh trong nước uống đóng chai tại khu vực Tây Nguyên qua các năm không có sự thay đổi.

\subsection{Tình trạng ô nhiễm nước uống đóng chai theo nguyên nhân}

Bảng 2. Nguyên nhân ô nhiếm nuớc uống đóng chai

\begin{tabular}{|c|c|c|c|c|c|c|c|c|c|}
\hline \multirow[b]{2}{*}{ Chỉ tiêu xét nghiệm } & \multicolumn{3}{|c|}{ Năm 2017} & \multicolumn{3}{|c|}{ Năm 2018} & \multicolumn{3}{|c|}{ Tổng cộng } \\
\hline & $\begin{array}{c}\text { Số mẫu } \\
X N\end{array}$ & $n$ & $(\%)$ & $\begin{array}{c}\text { Số mẫu } \\
X N\end{array}$ & $n$ & $(\%)$ & $\begin{array}{c}\text { Số mầu } \\
X N\end{array}$ & $n$ & $(\%)$ \\
\hline Coliform tổng số & 120 & 18 & 15,0 & 270 & 28 & 10,4 & 390 & 46 & 11,8 \\
\hline E.coli & 120 & 8 & 6,7 & 270 & 11 & 4,1 & 390 & 19 & 4,9 \\
\hline Streptococci facecal & 120 & 3 & 2,5 & 270 & 2 & 0,7 & 390 & 5 & 1,3 \\
\hline Clostridia & 120 & 9 & 7,5 & 270 & 9 & 3,3 & 390 & 18 & 4,6 \\
\hline P.aeruginosa & 120 & 53 & 44,2 & 270 & 109 & 40,4 & 390 & 162 & 41,5 \\
\hline
\end{tabular}


Nguyên nhân ô nhiễm vi sinh vật trong nước uống đóng chai chiếm tỷ lệ cao Pseudomonas aeruginosa chiếm $(41,5 \%)$ và Coliforms tổng số chiếm (11,8\%). Các vi khuẩn còn lại như Clostridia, Escherichia coli, Streptococci feacal tỷ lệ nhiễm tương đối thấp từ $(1-5 \%)$. Kết quả nghiên cứu này tương đồng với kết quả nghiên cứu của Nguyễn Vũ Thuận và cộng sự năm 2015, có 38,8\% mẫu nhiễm Pseudomonas aeruginosa và $14,6 \%$ mẫu nhiễm Coliforms tổng số [6]. Nhưng tỷ lệ nhiễm Pseudomonas aeruginosa nghiên cứu này cao hơn rất nhiều nghiên cứu Trần Thị Ánh Hồng và cộng sự năm 2012, có 2\% mẫu nhiễm Pseudomonas aeruginosa [3].

\subsection{Tình trạng ô nhiễm nước uống đóng chai theo địa điểm nghiên cứu}

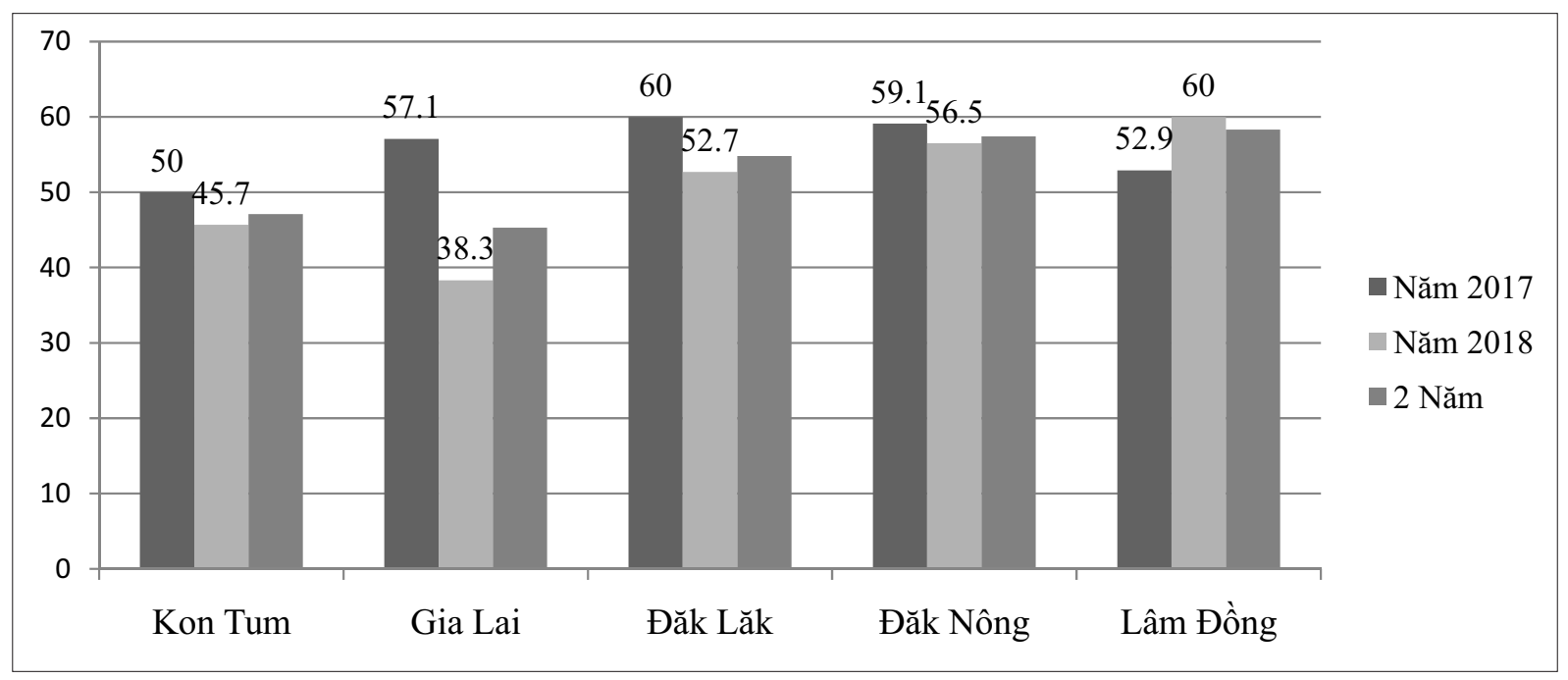

Hình 1. Tình trạng ô nhiễm nước uống đóng chai theo địa điểm nghiên cứu

Kết quả trên cho thấy, tỷ lệ ô nhiễm vi sinh nước uống đóng chai lấy trên địa bàn 5 tỉnh Tây Nguyễn (Kon Tum, Gia Lai, Đắk Lắk, Đăk Nông, Lâm Đồng) gần tương đương nhau. Trong đó tỷ lệ ô nhiễm tại Lâm Đồng cao nhất chiếm $(60 \%)$, Đăk Nông chiếm $(56,5 \%)$, Đắk Lắk chiếm $(52,7 \%)$, Kon Tum chiếm $(45,7 \%)$ và thấp nhất Gia Lai tỷ lệ ô nhiễm vi sinh vật chiếm $(38,3 \%)$. So với kết quả nghiên cứu Trần Thị Thanh Nga trên địa bàn tỉnh Hà Nam, Đỗ Huy Nhật Minh và cộng sự năm 2015 [4] [5] thì tình trạng ô nhiễm vi sinh trong nước uống đóng chai các tỉnh Tây Nguyên cao hơn rất nhiều.

\section{KẾT LUẬn VÀ KIẾN NGHI!}

\subsection{Kết luận}

Kết quả nghiên cứu 390 mẫu nước uống đóng chai tại khu vực 5 tỉnh Tây Nguyên giai đoạn năm 2017-2018 cho thấy:

Tỷ lệ nhiễm vi sinh vật trong nước uống đáng chai rất cao năm 2017 (56,7\%) và năm 2018 $(50,7 \%)$.

Nguyên nhân không đạt tiêu chuẩn vệ sinh về các chỉ tiêu vi sinh trong nước uống đóng chai chiếm tỷ lệ cao vi khuẩn Pseudomonas aeruginosa (41,5\%); Coliform tổng số $(11,8 \%)$ và thấp hơn nhiễm Clostridia (4,6\%); Escherichia coli (4,9\%); Streptococci feacal (1,3\%).

Tỷ lệ nhiễm vi sinh vật theo địa điểm nghiên cứu với Kon Tum (45,7\%), Gia Lai $(38,3 \%)$, Đắk Lắk (52,7\%), Đắk Nông (56,5\%), Lâm Đồng (60\%).

\subsection{Kiến nghị}

Cơ quan quản lý cần tăng cường công tác kiểm tra, giám sát sau cấp giấy chứng nhận An toàn vệ sinh thực phẩm, lấy mẫu hậu kiểm chất lượng nước uống lưu thông trên thị trường. 
Thường xuyên giám sát, kiểm tra các cơ sở sản xuất có tuân thủ đúng quy trình khép kín, một chiều, hệ thống lọc có định kỳ thay thế để loại bỏ được toàn bộ vi khuẩn và kim loại nặng không cần thiết trong nước, công nhân tham gia vào quy trình sản xuất phải có bảo đảm sức khỏe, kiến thức và tuân thủ các điều kiện, quy định về ATTP không. Ngoài ra, tăng cường kiểm tra điều kiện vệ sinh cơ sở, vệ sinh bình có đảm bảo không. Đối với các cơ sở nước uống đóng chai cố tình vi phạm, cơ quan chức năng cần kiên quyết xử lý nghiêm.

Tăng cường đưa ra các cảnh báo về vệ sinh an toàn thực phẩm không đảm bảo trên kênh thông tin đại chúng như: tivi, đài phát thanh,... để người tiêu dùng hiểu biết, phòng tránh sử dụng các sản phẩm nước uống đóng chai không đạt chất lượng thực phẩm.

\section{TÀI LIÊU THAM KHẢO}

1. Bộ Y Tế (2010), Quy chuẩn kỹ thuật quốc gia đối với nước khoáng thiên nhiên và nước uống đóng chai, QCVN 6-1:2010/BYT.

2. Bộ Y tế (2011), Thông tư 14/2011/TT-BYT hướng dẫn chung về lấy mẫu thực phẩm phục vụ thanh tra, kiểm tra chất lượng, vệ sinh an toàn thực phẩm.

3. Trần Thị Ánh Hồng và các cộng sự. (2012), "Nghiên cứu chất lượng nước uống đóng chai về mặt vi sinh vật trên địa bàn tỉnh Bình Định năm 2011", Tạp chí Y học thực hành (842), tr.135-140.

4. Đỗ Huy Nhật Minh và các cộng sự. (2015), "Khảo sát chất lượng nước uống đóng chai kiểm nghiệm tại Viện Pasteur Tp. Hồ Chí Minh năm 2015", Tạp Chí Dinh Duỡng \& Thực Phẩm (12), tr. 116-120.

5. Trần Thị Thanh Nga (2011), "Khảo sát chất lượng nước uống đóng chai trên địa bàn tỉnh Hà Nam năm 2011", Tạp chí Y học thực hành (842), tr. 119-121.

6. Nguyễn Vũ Thuận và các cộng sự. (2016), "Tình trạng ô nhiễm vi sinh và hóa lý trên một số sản phẩm thực phẩm bao gói sản xuất và lưu thông tại Tây Nguyên", Tạp Chí Dinh dương \& Thực phẩm, 12, tr. 350-354.

\section{Summary \\ BACTERIOLOGICAL ASSESSMENT OF BOTTLED DRINKING WATER IN 5 PROVINCES OF CENTRAL HIGHLAND, VIETNAM}

\section{Nguyen Vu Thuan, Pham Van Doanh, Nguyen Thi Thu Hien \\ Tay Nguyen Institute of Hygiene and Epidemiology}

The assessment of the bacteriological quality among 390 samples of bottled drinking water was studied. The samples were tested for Escherichia coli, Clostridia, total Coliform, Streptococci feacal and Pseudomonas aeruginosa. The rates of microbial contamination in bottled drinking water were of 56.7\% (2017) and 50.7\% (2018). The samples failed to meet QCVN drinking water standard of acceptable limits of bacterial presence including Pseudomonas aeruginosa (41.5\%), total Coliform (11.8\%), Clostridia (4.6\%); Escherichia coli (4.9\%) and Streptococcifeacal (1.3\%). It is necessary to strengthen the inspection, supervision, propagation, and education that give warnings, ensure water quality and raise the awareness of producers, traders and consumers.

Keyword: Bottled water, microbiological infection, water quality. 